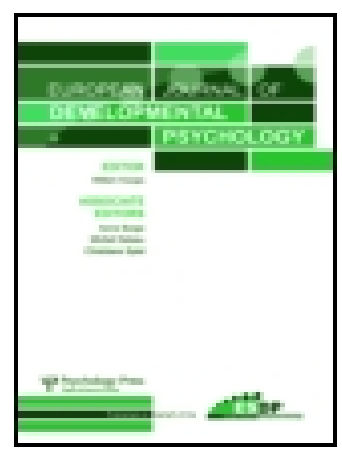

European Journal of Developmental Psychology

\title{
Alone at the playground
}

Guida Veiga, Lizet Ketelaar, Wendy De Leng, Ricardo Cachucho, Joost N. Kok, Arno Knobbe, Carlos Neto \& Carolien Rieffe

To cite this article: Guida Veiga, Lizet Ketelaar, Wendy De Leng, Ricardo Cachucho, Joost N. Kok, Arno Knobbe, Carlos Neto \& Carolien Rieffe (2016): Alone at the playground, European Journal of Developmental Psychology

To link to this article: http://dx.doi.org/10.1080/17405629.2016.1145111

曲 Published online: 17 Feb 2016.

Submit your article to this journal $\square$

Q View related articles $\longleftarrow$

View Crossmark data $־$ 


\title{
Alone at the playground
}

\author{
Guida Veigaa, ${ }^{\mathrm{a}, \mathrm{b}}$, Lizet Ketelaarr, ${ }^{\mathrm{c},}$, Wendy De Leng ${ }^{\mathrm{c}}$, Ricardo Cachucho ${ }^{\mathrm{e}}$, Joost \\ N. Kok ${ }^{e}$, Arno Knobbe ${ }^{e}$, Carlos Neto ${ }^{f}$ and Carolien Rieffe ${ }^{c, d}$
}

\begin{abstract}
aDepartamento de Desporto e Saúde, Escola de Ciências e Tecnologia, Universidade de Évora, Évora, Portugal; bLaboratory of Motor Behavior, Faculdade de Motricidade Humana, Universidade de Lisboa, Lisboa, Portugal; ' Developmental Psychology, Leiden University, Leiden, The Netherlands; ${ }^{\mathrm{d} D u t c h}$ Foundation for the Deaf and Hard of Hearing Child, Amsterdam, The Netherlands; 'eeiden Institute for Advanced Computer Science, Leiden University, Leiden, The Netherlands; ' Laboratory of Motor Behavior, CIPER, Faculdade de Motricidade Humana, Universidade de Lisboa, Lisboa, Portugal
\end{abstract}

\begin{abstract}
Starting pre-school is a major stepping stone for children's peer relations. Yet, some children spend their recess time alone, albeit in the presence of playful peers. These solitary behaviours have been noted in the literature as an alarm signal for a maladaptive social development. In this study, we identified four kinds of nonsocial behaviours engaged at recess (reticent, solitary-pretend, -functional, and -passive); and we examined the extent to which these different behaviours were related to social solitude at the playground six months later. Therefore, 97 children (aged 4-6 years old) were observed at the playground and their social-emotional skills were tested. Solitude was assessed through an innovative measuring method, based on Radio Frequency Identification Devices. The results demonstrated that solitary-pretend play in girls was related to an increase in solitary behaviours later on. Nevertheless, children who engaged in non-social behaviours showed a general lack of emotional skills, which may explain their initial withdrawal.
\end{abstract}

ARTICLE HISTORY Received 14 April 2015; Accepted 19 January 2016

KEYWORDS Non-social play; social withdrawal; social-emotional competence; playground; pre-school

Children play for intrinsic pleasure, while simultaneously practicing many skills which prepare them for later life (Coplan \& Arbeau, 2009). Additionally, playing with others, or so-called social play, also teaches children how to behave in groups, negotiate, and how to take their losses. This increases their social skills, whereas children who show a preference for solitary play, even when they are in the presence of peers, might be at a higher risk for an impaired social development (e.g., Coplan \& Armer, 2007; Rubin, Coplan, \& Bowker, 2009). 